\title{
Sequence variations of mitochondrial DNA D-loop region in patients with acute myeloid leukemia
}

\author{
JUAN ZHOU, HAIMEI GOU, YUANXIN YE, YI ZHOU, XIAOJUN LU and BINWU YING \\ Department of Laboratory Medicine, West China Hospital, Sichuan University, Chengdu, Sichuan 610041, P.R. China
}

Received April 3, 2016; Accepted June 22, 2017

DOI: $10.3892 / \mathrm{ol} .2017 .6988$

\begin{abstract}
The aim of the present study was to explore variations of the displacement (D)-loop region in patients with acute myeloid leukemia (AML) and their possible associations with AML pathogenesis. Blood or bone marrow samples from 216 patients with AML (158 AML patients in the first stage, and 58 more patients with AML-M3 for further verification), and 146 healthy controls were collected. Sanger sequencing was performed for the D-loop region ranging between nucleotide (nt)15811 and nt 775 . With the exception of mitochondrial microsatellite instability (mtMSI) variations, a total of 2,630 variations in 232 loci were identified with similar variation rates/person in patients with AML and controls when compared with the revised Cambridge reference sequence $(8.54 \pm 2.14$ vs. $8.77 \pm 2.15 ; \mathrm{P}=0.366)$. A positive association between AML and variation-T152C was identified, which occurred more frequently in patients with AML compared with in controls [26.6 vs. $17.1 \%$; $\mathrm{P}=0.048$; odds ratio (OR), 1.752; 95\% confidence interval (CI), 1.004-3.058]. Furthermore, T152C was identified to be associated with promyelocytic leukemia-retinoic acid receptor $\alpha(\operatorname{PML}-\mathrm{RAR} \alpha)$ and French-American-British AML subtypes, with a tendency to occur in patients with AML-M3. The AML-M3 sample size was extended by 58 cases, and it was identified that the T152C variation rate was significantly higher in patients with AML-M3 compared with that of controls (41.0 vs. 17.1\%; $\mathrm{P}<0.001$; OR, 3.228; 95\% CI, 1.714-6.079). However, no association was identified between the $\mathrm{T} 152 \mathrm{C}$ variation and clinical characteristics, or chemotherapy response in patients with AML-M3. In addition, the mtMSIs, including D310, mt514-523 $(\mathrm{CA})_{\mathrm{n}}$ and $\mathrm{T} 16189 \mathrm{C}$, demonstrated no association with AML risk. Together, the results of the present study suggest that the
\end{abstract}

Correspondence to: Professor Xiaojun $\mathrm{Lu}$ or Professor Binwu Ying, Department of Laboratory Medicine, West China Hospital, Sichuan University, 37 Guoxuexiang Road, Wuhou, Chengdu, Sichuan 610041, P.R. China

E-mail: luxiaojun1972@163.com

E-mail: bwydoc@163.com

Key words: acute myeloid leukemia, mitochondrial DNA, displacement-loop region, variation mitochondrial DNA D-loop region is high variable, and that T152C is associated with AML risk, particularly regarding the M3 subtype. T152C mayparticipate in AML pathogenesis and may be a diagnostic biomarker; however further studies with larger sample sizes are required in order to verify its value.

\section{Introduction}

Acute myeloid leukemia (AML) is a clinically and genetically heterogeneous disease manifested by hyperplasia, and differentiation retardation of one or more hematopoietic cell lineages. The therapeutic efficacy and the quality of life of patients with AML have improved in recent years, particularly for patients with acute promyelocytic leukemia, which can be attributed to the identification of molecular mechanisms underlying AML pathogenesis. Clonal chromosome alterations and fusion genes were firstly recognized, and were regarded as the most potent biomarkers for AML therapeutic response and survival prognosis (1). Subsequently, several gene mutations, including FLT3-internal tandem duplication, FLT3-tyrosine kinase domain, DNA methyltransferase $3 \alpha$, isocitrate dehydrogenase and CCAAT/enhancer binding protein $\alpha$ mutations, have been identified to participate in the abnormal proliferation of leukemia progenitor cells or impaired differentiation (2-4). In addition, they have been identified as valuable prognostic biomarkers that affect the therapeutic regimen decision (2-4). However, the aforementioned gene alterations alone have not fully elucidated the pathogenesis of AML, thus, current studies have focused on identifying novel biomarkers. The majority of studies have focused on the nuclear genome (2-5), with less focus on the extranuclear genome (mitochondrial genome).

It is well known that mitochondria are the energy supply center of the cell, and serve essential roles in cell apoptosis and signaling pathways, dysfunction of mitochondria have been considered to be associated with tumorigenesis (6). Variations in mitochondrial (mt)DNA that encode the key units of enzymes in the respiratory chain may cause mitochondrial dysfunction, particularly variations in the only non-coding region, the displacement (D)-loop region, which controls the mtDNA replication and transcription process. Furthermore, mtDNA is more vulnerable to external damage, due to naked DNA, reactive oxygen species (ROS) exposure, a high replication frequency and lack of an effective repair system; therefore, its mutation rate is higher compared with nuclear DNA $(7,8)$. The D-loop region variant frequency is higher 
compared with that of the coding region (9), it was reported that the mutation rate of certain areas in the D-loop region was 100-200-fold higher compared with nuclear DNA (10). mtDNA copy numbers are significantly higher compared with nuclear DNA (11). The aforementioned features enable higher sensitivity to marker detection of mtDNA compared with nuclear DNA, making it more feasible in research and clinical practice.

mtDNA variations have been investigated in various types of cancer, including lung cancer, breast carcinoma, liver cancer and cervical cancer, and have been reported to be associated with cancer susceptibility, progress and metastasis (12-15). In the hematological field, mtDNA variations in the D-loop region have also been reported (16-18), for instance, Kwok et al (17) proposed that polymorphisms in the D-loop region was associated with leukemia biology and therapy response. In this study, the results demonstrated that patients with T-cell acute lymphoblastic leukemia (T-ALL) possessed more $\mathrm{C}$ repetitions in the D310 poly-C region, the T199C variation increased the risk of ALL, and T152C variation was associated with improved response (17).

Several studies have also focused on mtDNA variations and AML, whereby an association has been identified between the two (19-21). However, a case-control study with a relatively larger sample size is lacking with little data from the Chinese population. Therefore, the present study was performed to explore the role of mtDNA D-loop variations in AML pathogenesis and therapy response, in the hope of identifying a novel mitochondrial biomarker for AML in the Chinese population.

\section{Materials and methods}

Study population. Diagnostic bone marrow or blood samples prior to treatment were obtained from 158 patients with AML diagnosed according to World Health Organization criteria (22) at West China Hospital of Sichuan University (Chengdu, China). Age- and sex-matched blood samples with normal hematologic indexes from 146 healthy controls attending a health checkup were also collected. Subjects with mtDNA mutation-associated diseases, including diabetes mellitus and deafness were excluded. To verify the association between T152C and AML-M3, the study was extended with 58 diagnostic AML-M3 samples. Written informed consent was obtained from all individuals and the present study was approved by the Ethical Committee of West China Hospital, Sichuan University.

Sequencing of mtDNA $D$-loop region. DNA was extracted from $200 \mu \mathrm{l}$ blood or bone marrow samples using aQIAamp DNA Mini kit (Qiagen GmbH, Hilden, Germany). Two overlapping fragments were amplified in order to cover the whole D-loop region, the primers are presented in Table I. Polymerase chain reaction (PCR) was performed in a final volume of $20 \mu \mathrm{l}$, comprising $2 \mu 1$ 10X PCR buffer $\left(\mathrm{Mg}^{2+}, 20 \mathrm{mM}\right), 0.5 \mu 1$ sense and antisense primers each $(10 \mu \mathrm{M}), 0.2 \mu 1$ TransStart Taq polymerase (1.5 U/ $\mu$ l; Beijing Transgen Biotech Co., Ltd., Beijing, China), $1 \mu \mathrm{l}$ DNA (20-50 ng/ $\mu \mathrm{l})$ and double-distilled water.

The reaction system was initially denatured at $95^{\circ} \mathrm{C}$ for $5 \mathrm{~min}$, followed by 40 cycles of denaturation at $95^{\circ} \mathrm{C}$ for
Table I. Primers applied to sequence the mitochondrial displacement-loop region.

\begin{tabular}{lcc}
\hline PCR primers & $\begin{array}{c}\text { 3'-position } \\
\left(5^{\prime}-3 '\right)\end{array}$ & Length $(n t)$ \\
\hline Mit23, F & & \\
TCATTGGACAAGTAGCATCC & 15,811 & 756 \\
Mit23, R & & \\
GAGTGGTTAATAGGGTGATAG & 5 & \\
Mit24, F & & \\
CACCATCCTCCGTGAAATCA & 16,420 & 954 \\
Mit24, R & & \\
AGGCTAAGCGTTTTGAGCTG & 775 & \\
\hline
\end{tabular}

$45 \mathrm{sec}$, annealing at $58^{\circ} \mathrm{C}$ for $30 \mathrm{sec}$, and extension at $72^{\circ} \mathrm{C}$ for $45 \mathrm{sec}$, followed by a final extension performed at $72^{\circ} \mathrm{C}$ for $5 \mathrm{~min}$. Subsequently, the PCR products were purified using SAP mix (Fermentas; Thermo Fisher Scientific, Inc., Pittsburgh, PA, USA). Cycle sequencing was then performed in a volume of $10 \mu \mathrm{l}$ using a BigDye ${ }^{\circledR}$ Terminator v3.1 cycle Sequencing kit, the sense and antisense primers were separately used as sequencing primers for forward and reverse sequencing, respectively. PCR and cycle sequencing were performed using a PCR System 2720 (Applied Biosystems; Thermo Fisher Scientific, Inc.). The cycle sequencing product was purified using a BigDyeXTerminator Purification kit (Applied Biosystems; Thermo Fisher Scientific, Inc.), followed by capillary electrophoresis in an ABI 3130 automated DNA analyzer (Applied Biosystems; Thermo Fisher Scientific, Inc.).

Chromas 2.23 (Technelysium Pty Ltd., South Brisbane, Australia) was used to read the sequencing results, and Lasergene-Seqman software (version 7.0; DNASTAR, Inc., Madison, WI, USA) was used to splice the four fragments in each sample, based on the revised Cambridge reference sequence (NC_012920.1), generating complete D-loop DNA sequences (mt16024-mt16569 and mt1-mt576, according to NC_012920.1). Finally, the DNA sequences were aligned to the revised Cambridge reference sequence by the CodonCode Aligner software (version 4.0.4; CodonCode Corporation, Centerville, MA, USA) for comparison.

Statistical analysis. Data are presented as the mean \pm standard deviation or median (interquartile range) for continuous variables, and as frequencies (percentages) for categorical variables. Variation frequency differences between cases and controls were analyzed using PLINK software (version 1.07; zzz.bwh.harvard.edu/plink), except for multiple alleles loci and mitochondrial microsatellite instability (mtMSI) variations [including D310, mt514-523 (CA) and T16189C], which were analyzed using SPSS software (version 17.0 SPSS, Inc., Chicago, IL, USA), using regression analysis, adjusted by age and sex. Association analysis between mitochondrial variations and clinical characteristics were performed using SPSS. Qualitative data were analyzed using $\chi^{2}$ or Fisher's exact tests. Quantitative data were analyzed using unpaired t-test or 
Table II. Basic characteristics of patients with AML and control subjects.

\begin{tabular}{|c|c|c|c|}
\hline Characteristic & $\begin{array}{c}\text { AML } \\
(n=158)\end{array}$ & $\begin{array}{l}\text { Control } \\
(n=146)\end{array}$ & P-value \\
\hline Sex, female/male & $72 / 86$ & $66 / 80$ & 0.949 \\
\hline Age, years ${ }^{\mathrm{a}}$ & $42.37 \pm 16.00$ & $41.63 \pm 12.56$ & 0.651 \\
\hline \multicolumn{4}{|l|}{ Fusion gene, n (\%) } \\
\hline AML1-ETO & $20(12.7)$ & & \\
\hline $\mathrm{CBF} \beta / \mathrm{MYH}$ & $9(5.7)$ & & \\
\hline PML-RAR $\alpha$ & $17(10.8)$ & & \\
\hline \multicolumn{4}{|l|}{ Peripheral blood ${ }^{\mathrm{b}}$} \\
\hline $\mathrm{Hb}, \mathrm{g} / \mathrm{l}$ & $76.00(60.50-100.50)$ & & \\
\hline WBC, $\times 10^{9}$ cells $/ 1$ & $13.75(4.23-55.70)$ & & \\
\hline PLT, $x 10^{9}$ cells/1 & $23.00(12.00-47.50)$ & & \\
\hline Hypocytosis, n (\%) & $26(16.5)$ & & \\
\hline HLAL, n $(\%)$ & $23(14.6)$ & & \\
\hline Bone marrow blast cell, $\%{ }^{\mathrm{b}}$ & $73.00(45.00-90.00)$ & & \\
\hline
\end{tabular}

${ }^{a}$ Data are presented as the mean \pm standard deviation. ${ }^{b}$ Data are presented as the median (interquartile range). HLAL, hyperleukocytic acute leukemia; AML, acute myeloid leukemia; ETO, eight-twenty-one oncoprotein; CBF $\beta$, core-binding transcription factor $\beta$; MYH, myosin heavy chain; PML, promyelocytic leukemia; RAR $\alpha$, retinoic acid $\alpha$ receptor; WBC, white blood cell; PLT, platelet; Hb, hemoglobin; SD, standard deviation.

Table III. D310 variation pattern distribution in patients with AML and the control group.

\begin{tabular}{|c|c|c|c|c|c|c|c|c|c|}
\hline \multirow[b]{2}{*}{ Group } & \multirow[b]{2}{*}{ Total } & \multicolumn{8}{|c|}{ D310 variation distribution (\%) } \\
\hline & & $\mathrm{C}_{6} \mathrm{TC}_{6}$ & $\mathrm{C}_{7} \mathrm{TC}_{6}$ & $\mathrm{C}_{8} \mathrm{TC}_{6}$ & $\mathrm{C}_{9} \mathrm{TC}_{6}$ & $\mathrm{C}_{10} \mathrm{TC}_{6}$ & $\mathrm{C}_{7} \mathrm{TC}_{7}$ & $\mathrm{C}_{11}$ & P-value \\
\hline Control & 146 & $1(0.7)$ & $58(39.7)$ & $54(37.0)$ & $27(18.5)$ & $4(2.7)$ & $1(0.7)$ & $1(0.7)$ & 0.653 \\
\hline AML & 158 & $2(1.3)$ & $57(36.1)$ & $71(44.9)$ & $21(13.3)$ & $5(3.2)$ & $0(0.0)$ & $2(1.3)$ & \\
\hline Total & 304 & $3(1.0)$ & $115(37.8)$ & $125(41.1)$ & $48(15.8)$ & $9(3.0)$ & $1(0.3)$ & $3(1.0)$ & \\
\hline
\end{tabular}

AML, acute myeloid leukemia.

Mann-Whitney U test. Association analysis between chemotherapy remission and mitochondrial variations was analyzed using the Kaplan-Meier estimator method.

\section{Results}

Basic characteristics of patients with AML and control subjects. A total of 158 AML patients, and 146 age (42.37 \pm 16.00 vs. $41.63 \pm 12.56$, years; $\mathrm{P}=0.651$ ) and sex (female $/ \mathrm{male}, 72 / 86$ vs. $66 / 80 ; \mathrm{P}=0.949)$ matched healthy controls were included in the present study, as presented in Table II. There were 7 French-American-British (FAB)AML subtypes as follows: $\mathrm{M}_{0}, 4 ; \mathrm{M}_{1}, 35 ; \mathrm{M}_{2}, 41 ; \mathrm{M}_{3}, 20 ; \mathrm{M}_{4}, 30\left(\mathrm{M}_{4 \mathrm{EO}}, 5\right) ; \mathrm{M}_{5}, 27$; and $\mathrm{M}_{6}, 1$. The median values of hemoglobin ( $\left.\mathrm{Hb}\right)$, white blood cell (WBC) and platelet (PLT) were $76.00 \mathrm{~g} / 1,13.75 \times 10^{9}$ cells $/ 1$ and $23.00 \times 10^{9}$ cells $/ 1$, respectively, all of which were out of the reference range. In addition, $16.5 \%$ patients were hypocytic and $14.6 \%$ patients exhibited hyperleukocytic acute leukemia (HLAL), with the median blast cell percentage in the bone marrow being $73.00 \%$. Fusion genes frequently identified in patients with AML were detected, including AML1-eight-twenty-oneoncoprotein (ETO), core-binding transcription factor $\beta(\mathrm{CBF} \beta) /$ myosin heavy chain $(\mathrm{MYH})$ and promyelocytic leukemia (PML)-retinoic acid receptor $\alpha(\mathrm{RAR} \alpha)$, with positive rates of $12.7,5.7$ and $10.1 \%$, respectively.

Association between mtDNA D-loop variations and AML risk Special mtDNA variations-mtMSIs. Several special mtDNA variations, including D310, T16189C and mt514-mt523 (CA) repeat, were identified with unstable regions caused by insertions or deletions, and being recognized as mtMSIs.

D310 is a poly-C repeat stretch within the D-loop region, which is the main mtMSI. The sequence of D310 was 'CCC CCCCTCCCCC' (denoted as $\mathrm{C}_{7} \mathrm{TC}_{5}$ ) in the revised Cambridge reference sequence, and the number of $\mathrm{C}$ bases varies in different subjects (23). In the present study, seven variation patterns were identified; the majority held a $\mathrm{C}_{\mathrm{n}} \mathrm{TC}_{6}$ pattern (n, 6-10), 
Table IV. T16189C and 514-523 (CA $)$ variation pattern distribution in patients with AML and the control group.

\begin{tabular}{|c|c|c|c|c|c|c|c|c|c|}
\hline \multirow[b]{2}{*}{ Group } & \multirow[b]{2}{*}{ Total } & \multicolumn{3}{|c|}{ T16189C } & \multicolumn{5}{|c|}{$514-523\left(\mathrm{CA}_{\mathrm{n}}\right)$} \\
\hline & & $\mathrm{T}(\%)$ & $\mathrm{C}(\%)$ & P-value & $\mathrm{CA}_{4}(\%)$ & $\mathrm{CA}_{5}(\%)$ & $\mathrm{CA}_{6}(\%)$ & $\mathrm{CA}_{7}(\%)$ & P-value \\
\hline Control & 146 & $91(62.3)$ & $55(37.7)$ & & $60(41.1)$ & $86(58.9)$ & $0(0.0)$ & $0(0.0)$ & 0.533 \\
\hline AML & 158 & 107 (67.7) & $51(32.3)$ & 0.324 & $59(37.3)$ & $96(60.8)$ & $2(1.3)$ & $1(0.6)$ & \\
\hline Total & 304 & $198(65.1)$ & $106(34.9)$ & & $119(39.1)$ & $182(59.9)$ & $2(0.7)$ & $1(0.3)$ & \\
\hline
\end{tabular}

AML, acute myeloid leukemia.

Table V. High frequency variation loci in the Chinese Han population.

\begin{tabular}{|c|c|c|c|c|c|c|c|c|}
\hline \multirow[b]{2}{*}{ Locus } & \multirow[b]{2}{*}{ Base change } & \multirow[b]{2}{*}{ Region } & \multicolumn{2}{|c|}{ Total } & \multicolumn{2}{|c|}{ Case group } & \multicolumn{2}{|c|}{ Control group } \\
\hline & & & $\mathrm{n}$ & $\%$ & $\mathrm{n}$ & $\%$ & $\mathrm{n}$ & $\%$ \\
\hline 73 & A-G & HVII & 303 & 99.7 & 157 & 99.4 & 146 & 100.0 \\
\hline 263 & $A-G$ & HVII & 298 & 98.0 & 156 & 98.7 & 142 & 97.3 \\
\hline 16223 & C-T & HVI & 188 & 61.8 & 100 & 63.3 & 88 & 60.3 \\
\hline 489 & T-C & HVIII & 161 & 53.0 & 87 & 55.1 & 74 & 50.7 \\
\hline
\end{tabular}

HV, hypervariable.

whereby $\mathrm{C}_{7} \mathrm{TC}_{6}, \mathrm{C}_{8} \mathrm{TC}_{6}$ and $\mathrm{C}_{9} \mathrm{TC}_{6}$ were dominant, accounting for $37.8,41.1$, and $15.8 \%$, respectively. In addition, $\mathrm{C}_{7} \mathrm{TC}_{7}$ and $\mathrm{C}_{11}$ patterns were identified, as presented in Table III. However, no significant difference was identified in the D310 variation distribution between patients with AML and the control group $(\mathrm{P}=0.653)$.

Another highly variable poly-C domain exists in the D-loop region ranging between $\mathrm{mt} 16180$ and $\mathrm{mt} 16193$, the sequence is 'AAAACCCCCTCCCC' (denoted as $\mathrm{A}_{4} \mathrm{C}_{5} \mathrm{TC}_{4}$ ). It was reported that a T-C transition (termed as T16189C) occurred in $30 \%$ of Asian people (24), forming a poly-C structure, which was reported to be a disease association research hotspot (25). However, no significant difference was identified in the frequency of $\mathrm{T} 16189 \mathrm{C}$ between patients with $\mathrm{AML}$ and the controls (32.3 vs. $37.7 \%$; $\mathrm{P}=0.324)$, as presented in Table IV.

The $(\mathrm{CA})_{\mathrm{n}}$ repeat is a length polymorphism located in $\mathrm{mt514}-\mathrm{mt} 523$, the repeat number varies between 3 and 7 . In the present study, $\mathrm{CA}_{4}-\mathrm{CA}_{7}$ repeats were identified, with $\mathrm{CA}_{4}$ and $\mathrm{CA}_{5}$ being the most dominant, accounting for 39.1 , and $59.9 \%$, respectively. $\mathrm{CA}_{6}$ (2 cases) and $\mathrm{CA}_{7}$ (1 case) repeats were identified only in patients with AML. However, no significant differences were identified in the 514-523 $\left(\mathrm{CA}_{\mathrm{n}}\right)$ distribution between cases and controls $(\mathrm{P}=0.533)$.

Point variations in $m t D N A$ D-loop region. Besides the aforementioned special mitochondrial variations, a total of 2,630 variations (AML, 1,350 variations; controls, 1,280 variations) in 232 loci were identified, with similar variation numbers per person observed in patients and controls $(8.54 \pm 2.14$ vs. $8.77 \pm 2.15 ; \mathrm{P}=0.366$ ), suggesting a high variability in the D-loop region. Based on the revised Cambridge reference sequence (26), four loci in the D-loop region were identified
Table VI. Variation loci in patients with AML only or in control group only.

\begin{tabular}{|c|c|c|c|c|c|c|}
\hline \multirow[b]{2}{*}{ Locus } & \multirow[b]{2}{*}{ Base change } & \multirow[b]{2}{*}{ Region } & \multicolumn{2}{|c|}{$\begin{array}{l}\text { Case } \\
\text { group }\end{array}$} & \multicolumn{2}{|c|}{$\begin{array}{l}\text { Control } \\
\text { group }\end{array}$} \\
\hline & & & $\mathrm{n}$ & $\%$ & $\mathrm{n}$ & $\%$ \\
\hline 16145 & G-A & HVI & 0 & 0.00 & 3 & 2.05 \\
\hline 16167 & $\mathrm{C}-\mathrm{T}$ & HVI & 0 & 0.00 & 3 & 2.05 \\
\hline 16248 & $\mathrm{C}-\mathrm{T}$ & HVI & 0 & 0.00 & 3 & 2.05 \\
\hline 16176 & C-T & HVI & 0 & 0.00 & 4 & 2.74 \\
\hline 16302 & $A-G$ & HVI & 0 & 0.00 & 4 & 2.74 \\
\hline 16134 & C-T & HVI & 3 & 1.90 & 0 & 0.00 \\
\hline 185 & G-A & HVII & 3 & 1.90 & 0 & 0.00 \\
\hline 16051 & $A-G$ & HVI & 4 & 2.53 & 0 & 0.00 \\
\hline 16526 & G-A & 1 & 4 & 2.53 & 0 & 0.00 \\
\hline
\end{tabular}

HV, hypervariable; AML, acute myeloid leukemia.

to be highly variable in the Chinese Han population, with frequencies $>50 \%$, as presented in Table $\mathrm{V}$.

Variations in 57 loci were identified only in the control group, of which, variation frequencies of 45 loci were $0.68 \%$ (1 subject), variation frequencies of seven loci were $1.37 \%$ (2 subjects), variation frequencies of three loci were $2.05 \%$ (3 subjects), and variation frequencies of two loci were $2.74 \%$ (4 subjects). In addition, variations in 67 loci were identified only in patients with AML, of which, variation frequencies of 55 loci were $0.63 \%$ (1 subject), variation 
Table VII. T152C variation distribution and its association with AML characteristics.

\begin{tabular}{|c|c|c|c|}
\hline Variable & $\mathrm{T}$ & $\mathrm{C}$ & P-value \\
\hline \multicolumn{4}{|l|}{ Case-control } \\
\hline $\operatorname{AML}(\%)$ & $116(73.4)$ & $42(26.6)$ & $\begin{array}{c}0.048(\mathrm{OR}, 1.752 ; 95 \% \\
\text { CI, } 1.004-3.058)^{\mathrm{a}}\end{array}$ \\
\hline Control group (\%) & $121(82.9)$ & $25(17.1)$ & \\
\hline \multicolumn{4}{|l|}{ AML characteristics } \\
\hline Sex (female/male) & $52 / 64$ & $20 / 22$ & 0.756 \\
\hline Age (years, mean \pm SD) & $43.91 \pm 16.50$ & $38.12 \pm 13.87$ & 0.044 \\
\hline \multicolumn{4}{|l|}{ Peripheral blood [median(P25-P75)] } \\
\hline $\mathrm{Hb}(\mathrm{g} / \mathrm{l})$ & $79.0(60.5-99.5)$ & $70.0(60.0-103.3)$ & 0.728 \\
\hline WBC $\left(\times 10^{9}\right.$ cells $\left./ 1\right)$ & $12.3(4.1-52.2)$ & $20.5(5.0-66.4)$ & 0.261 \\
\hline PLT $\left(x 10^{9}\right.$ cells $\left./ 1\right)$ & $23.0(12.0-48.0)$ & $22.0(12.8-47.5)$ & 0.800 \\
\hline Hypocytosis, n (\%) & $19(16.4)$ & $7(16.7)$ & 0.983 \\
\hline HLAL, n $(\%)$ & $16(13.8)$ & $7(16.7)$ & 0.696 \\
\hline Blast cell $[\%$, median $(\mathrm{P} 25-\mathrm{P} 75)]$ & $71.0(44.0-89.5)$ & $81.0(54.5-91.0)$ & 0.284 \\
\hline \multicolumn{4}{|l|}{ Fusion gene } \\
\hline AML1-ETO & $12(10.3 \%)$ & $8(19.0 \%)$ & 0.146 \\
\hline $\mathrm{CBF} \beta / \mathrm{MYH}$ & $5(4.3 \%)$ & $4(9.5 \%)$ & 0.248 \\
\hline PML-RAR $\alpha$ & $6(5.2 \%)$ & $11(26.2 \%)$ & $\begin{array}{c}0.001 \text { (OR, 6.49; } \\
95 \% \text { CI, 2.23-18.87) }\end{array}$ \\
\hline FAB subtypes & & & 0.010 \\
\hline M0 & $3(2.6 \%)$ & $1(2.4 \%)$ & \\
\hline $\mathrm{M} 1 / \mathrm{M} 2$ & $59(50.9 \%)$ & $17(40.5 \%)$ & \\
\hline M3 & $8(6.9 \%)$ & $12(28.6 \%)$ & \\
\hline M4/M5 & $45(38.8 \%)$ & $12(28.6 \%)$ & \\
\hline M6 & $1(0.9 \%)$ & $0(0.0 \%)$ & \\
\hline
\end{tabular}

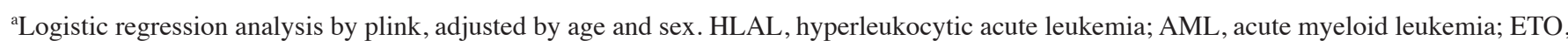
eight-twenty- one oncoprotein; CBF $\beta$, core-binding transcription factor $\beta ; \mathrm{MYH}$, myosin heavy chain; PML, promyelocytic leukemia; RAR $\alpha$, retinoic acid $\alpha$ receptor; WBC, white blood cell; PLT, platelet; $\mathrm{Hb}$, hemoglobin; $\mathrm{SD}$, standard deviation; OR, odds ratio; CI, confidence interval; FAB, French-American-British.

frequencies of eight loci were $1.27 \%$ (2 subjects), variation frequencies of two loci were $1.90 \%$ (3 subjects), and variation frequencies of two loci were $2.53 \%$ (4 subjects). These variation loci maybe significant in AML pathogenesis; however, the variations with relatively higher frequencies were all polymorphisms, as described on www.mitomap.org or mtDB (www.genpat.uu.se/mtDB) databases. No significant difference between cases and controls were identified, as presented in Table VI. Furthermore, several variations with low frequencies were not identified in the two databases; thus, they maybe mutations. However, they were of insignificant value due to the low occurrence rate and were not suitable as biomarkers.

Association analysis of the 232 variation loci with AML onset revealed one positive association variation locus-T152C, using logistic regression analysis adjusted by age and sex. T152C occurred more frequently in patients with AML compared with in controls (26.6 vs. $17.1 \%$; $\mathrm{P}=0.048$ ), subjects carrying $\mathrm{T} 152 \mathrm{C}$ were at a 1.752 -fold risk of AML compared with subjects without $\mathrm{T} 152 \mathrm{C}$ [odds ratio (OR), 1.752, 95\% confidence interval (CI), 1.004-3.058; Table VII].
Association between $T 152 C$ variation and AML clinical characteristics. Clinical characteristics, including sex, age, peripheral blood indexes, HLAL, blast cell in bone marrow, fusion genes and FAB subtypes, were compared between patients with AML carrying the $\mathrm{T}$ allele, and those carrying the $\mathrm{C}$ allele as presented in Table VII.

It was demonstrated that $\mathrm{T} 152 \mathrm{C}$ frequency was similar between females and males $(\mathrm{P}=0.756)$, while patients carrying $\mathrm{T} 152 \mathrm{C}$ variation appears to be significantly younger compared with patients without T152C (38.12 13.87 vs. $43.91 \pm 16.50 ; \mathrm{P}=0.044)$. As for peripheral blood indexes, it was revealed that the median of $\mathrm{Hb}$ and PLT were below normal, and $\mathrm{WBC}$ was above normal, whether in patients with $\mathrm{T} 152 \mathrm{C}$ or without $\mathrm{T} 152 \mathrm{C}$, no significant difference was identified (All $\mathrm{P}>0.05$ ). The frequencies of hypocytosis and HLAL demonstrated no significant difference between patients with or without $\mathrm{T} 152 \mathrm{C}$. The blast cell percentage in the bone marrow was slightly higher in patients carrying T152C variation $\left[81.0 \%\left(\mathrm{P}_{25}-\mathrm{P}_{75}, 54.5-91.0\right)\right.$ vs. $71.0 \%$ $\left.\left(\mathrm{P}_{25}-\mathrm{P}_{75}, 44.0-89.5\right)\right]$; however, this did not reach a significant level $(\mathrm{P}=0.284)$. 
Table VIII. Clinical characteristics between patients with AML-M3 carrying the T allele, and those carrying the C allele.

\begin{tabular}{|c|c|c|c|c|}
\hline \multirow[b]{2}{*}{ Characteristic } & \multicolumn{4}{|c|}{ Patients with AML-M3 (T152C variation) } \\
\hline & Total $(n=78)$ & $T(n=46)$ & $C(n=32)$ & P-value \\
\hline Sex (female/male) & $31 / 47$ & $23 / 23$ & $8 / 24$ & $0.026^{\mathrm{a}}$ \\
\hline Age (years, mean $\pm \mathrm{SD}$ ) & $39.21 \pm 13.11$ & $41.04 \pm 14.21$ & $36.56 \pm 11.03$ & 0.139 \\
\hline \multicolumn{5}{|l|}{ Peripheral blood [median $\left(\mathrm{P}_{25}-\mathrm{P}_{75}\right)$ ] } \\
\hline $\mathrm{Hb}(\mathrm{g} / \mathrm{l})$ & $73.50(63.75-103.00)$ & $73.50(65.25-100.50)$ & $74.00(57.75-110.50)$ & 0.851 \\
\hline WBC $\left(\times 10^{9}\right.$ cells/l) & $3.66(1.44-11.25)$ & $2.81(1.27-8.39)$ & $5.16(2.04-17.24)$ & 0.065 \\
\hline PLT $\left(\times 10^{9}\right.$ cells/l) & $15.00(10.00-29.00)$ & $13.50(10.00-27.00)$ & $18.50(10.75-31.25)$ & 0.427 \\
\hline Hypocytosis, n (\%) & $31(39.7)$ & $19(41.3)$ & $12(37.5)$ & 0.785 \\
\hline HLAL, n $(\%)$ & $5(6.4)$ & $2(4.3)$ & $3(9.4)$ & 0.390 \\
\hline PML-RAR $\alpha, \mathrm{n}(\%)$ & $72(92.3)$ & $41(89.1)$ & $31(96.9)$ & 0.392 \\
\hline \multicolumn{5}{|l|}{ Chemotherapy response $\mathrm{b}^{\mathrm{b}}$} \\
\hline Remission at third month, $\mathrm{n}(\%)$ & $53(93.0)$ & $31(91.2)$ & $22(95.7)$ & 1.000 \\
\hline $\begin{array}{l}\text { Remission duration [days, } \\
\left.\text { median }\left(\mathrm{P}_{25}-\mathrm{P}_{75}\right)\right]\end{array}$ & $42.00(34.00-60.00)$ & $44.00(35.00-61.75)$ & $41.00(34.00-57.00)$ & 0.782 \\
\hline
\end{tabular}

${ }^{\mathrm{a}} \mathrm{OR}, 3.000,95 \% \mathrm{CI}, 1.118-8.050$; ${ }^{\mathrm{b}} \mathrm{Completeclinical} \mathrm{data} \mathrm{were} \mathrm{collected} \mathrm{from} 57$ cases, 23 cases of which carried T152C variation. HLAL, hyperleukocytic acute leukemia; AML, acute myeloid leukemia; PML, promyelocytic leukemia; RAR $\alpha$, retinoic acid $\alpha$ receptor; WBC, white blood cell; PLT, platelet; Hb, hemoglobin; SD, standard deviation; OR, odds ratio; CI, confidence interval.

AML1-ETO, CBFß/MYH and PML-RAR $\alpha$ were the most common fusion genes in patients with AML, the occurrence frequencies were all higher in patients with T152C compared with patients without $\mathrm{T} 152 \mathrm{C}$; however, only the difference in PML-RAR $\alpha$ was identified to be significant $(\mathrm{P}=0.001)$. The PML-RAR $\alpha$-positive rate was $26.2 \%$ in patients with T152C and $5.2 \%$ in patients without T152C (OR, 6.49;95\% CI, 2.23-18.87). Correspondingly, the FAB subtype distribution was associated with $\mathrm{T} 152 \mathrm{C}$ variation $(\mathrm{P}=0.010)$, the percentage of AML-M3 was higher in patients with T152C compared with those without (28.6 vs. $6.9 \%$ ), while the percentages of other subtypes were slightly lower in patients with T152C.

Association between T152C variation, and AML-M3 risk and clinical characteristics. Since AML-M3 was identified to be associated with T152C variation, the AML-M3 group was extended with 58 more patients with AML-M3 to give a final sample size of 78 patients. It was demonstrated that $\mathrm{T} 152 \mathrm{C}$ variation rate was significantly higher in patients with M3 (41.0\%, 32/78) compared with in controls $(17.1 \%, 25 / 146)$. The OR of M3 risk was 3.228 ( $\mathrm{P}<0.001 ; 95 \%$ CI, 1.714-6.079), using logistic regression analysis adjusted by age and sex.

Furthermore, the association between T152C and clinical characteristics was assessed, as presented in Table VIII. It revealed that $\mathrm{T} 152 \mathrm{C}$ occurred significantly more often in males (51.1\%) compared with in females (25.8\%) $(\mathrm{P}=0.026$; OR, 3.000; 95\% CI, 1.118-8.050). The patients with AML-M3 and T152C were also younger $(36.56 \pm 11.03$ vs. $41.04 \pm 14.21)$; however, no significant difference was identified $(\mathrm{P}=0.139)$. As for the peripheral blood indexes, the medians of $\mathrm{Hb}, \mathrm{WBC}$ and PLT were all below normal, demonstrating no significant difference between patients with or without T152C. The frequencies of hypocytosis and HLAL were similar in the two groups.
PML-RAR $\alpha$ demonstrated no significant difference between M3 patients with or without $\mathrm{T} 152 \mathrm{C}(\mathrm{P}=0.392)$. Chemotherapy response was also evaluated in 57 patients with AML-M3 whose follow-up data were complete, using a Mann-Whitney U test. In the patients carrying the $\mathrm{T}$ allele and patients carrying the $\mathrm{C}$ allele, the remission rates at the third month were 91.2, and $95.7 \%$, with the remission durations being 44.00 and 41.00 days, respectively, demonstrating no significant difference.

\section{Discussion}

mtDNA variations, particularly the control region, the D-loop region, have been reported to participate in carcinogenesis $(27,28)$. Grist et al (19) sequenced the D-loop region in 22 patients with AML, and reported the majority of mtDNA mutations occurred during the growth of the leukemic clone, and evolved during AML progression; they tended to occur at hotspots rather than be randomly distributed. Sharawat et al (20) sequenced the D-loop region in 44 pediatric patients with AML, demonstrating a high frequency of mtDNA variations, and identified three variations $(16126 \mathrm{~T}>\mathrm{C}$, $16224 \mathrm{~T}>\mathrm{C}$ and $16311 \mathrm{~T}>\mathrm{C}$ ) that were significantly associated with inferior event-free survival. Silkjaer et al (21) sequenced the entire mtDNA in 56 patients with AML and 14 control subjects. This study identified that the T16311C variation was the most frequent variation in the control region and tended to be associated with chromosomal abnormalities (21). In the present study, the D-loop region in 158 AML patients and 146 controls was sequenced, which revealed high variability in all subjects. In addition, T152C variation was identified to be associated with AML onset; however, no significant differences were identified in the mtMSIs in the mtDNA D-loop region between patients with AML and controls, including D310, 
T16189C, and mt514-mt523 (CA) repeat. Consistent with the aforementioned studies (19-21), the results of the current study also suggested that mtDNA variation served roles in AML pathogenesis. The current study was a case-control study, which focused on the genetic background of AML from the aspects of mtDNA and identifying mitochondrial biomarkers for AML. Furthermore, the sample size was relatively higher in the current study and was first studied in a Chinese population.

A total of 2,630 variations were identified in 232 loci (accounting for $21 \%(232 / 1,122)$ of the D-loop region) with the exception of mtMSIs in the D-loop region, $\sim 8$ variations/person occurred, suggesting high variability in the D-loop region. One reason was ethnic differences, as the variations were based on the revised Cambridge reference sequence, which was Caucasian-based, and the other reason was the high mutation rate of mtDNA, particularly within the D-loop region. mtDNA mutations have been identified in the majority of cancer types, including breast cancer (14), colorectal cancer (29) and acute lymphoblastic leukemia (18); however, the mutations identified were predominantly polymorphisms. In addition, previous studies have revealed that mtDNA polymorphisms were associated with pathogenesis and prognosis (30-32). For example, $200 \mathrm{G} / \mathrm{A}$ and $16362 \mathrm{~T} / \mathrm{C}$ polymorphisms were identified to be predictive markers for age-at-onset of non-small cell lung cancer (30). Furthermore, a study reported that high mtDNA content plus 10398A may be a marker of poor prognosis in cervical cancer (31). Lam et al (32) reported five mtDNA polymorphisms associated with pancreatic cancer risk in a study with 286 cases and 283 controls. In the present study, the total variation frequency was similar between cases and controls, suggesting that the majority of variations were polymorphisms unassociated with pathogenesis, and a case-control design may aid in identifying disease-associated variations.

In the present study, $\mathrm{T} 152 \mathrm{C}$ variation was identified to be associated with AML onset, subjects carrying T152C were at a 1.752-fold risk of AML compared with subjects with the $\mathrm{T}$ allele. $\mathrm{T} 152 \mathrm{C}$ is located at an important region, the origin of $\mathrm{O}_{\mathrm{H}}$ (nucleotides 146 to 199). Polymorphisms around $\mathrm{O}_{\mathrm{H}}$ may enhance replication, and confer a survival advantage for leukemia cells, leading to uncontrolled proliferation and oncogenesis (17). For instance, C150T and A189G were observed to be associated with longevity in the elderly $(33,34)$. Furthermore, T152C was identified to be associated with a more improved response to chemotherapy in patients with ALL (17). It was speculated that the increased replicative advantage leads to increased ROS production, which made the cancer cells more susceptible to apoptosis following chemotherapy (17). However, no association was identified between $\mathrm{T} 152 \mathrm{C}$ variation and the majority of AML characteristics, including WBC, PLT, and $\mathrm{Hb}$ in peripheral blood, the frequencies of hypocytosis and HLAL, the blast cell percentage in the bone marrow, AML1-ETO and CBF $\beta / \mathrm{MYH}$ fusion genes, while T152C was associated with PML-RAR $\alpha$ fusion gene and FAB subtypes. The T152C variation frequency was identified to be higher in patients with AML-M3, which were primarily PML-RAR $\alpha$-positive. This positive association remained following extension of the sample size of patients with AML-M3 with the odds ratio of M3 risk being 3.228; however, no association was identified between T152C and clinical characteristics in patients with AML-M3. The association between $\mathrm{T} 152 \mathrm{C}$ and chemotherapy response in patients with AML-M3 was further analyzed, but no association was identified, inconsistent with ALL patients (17), which may be caused by the different mechanisms of the chemotherapeutic drug, all trans retinoic acid for AML-M3, which primarily induces differentiation. Furthermore, no association was identified between PML-RAR $\alpha$ and T152C in patients with AML-M3, suggesting that the positive association observed between PML-RAR $\alpha$ and T152C in AML patients may due to the high positive rates of PML-RAR $\alpha$ in the M3 subtype, rather than a true association between PML-RAR $\alpha$ and T152C.

mtMSIs have been identified in various cancer types, and have been demonstrated to participate in carcinogenesis and be associated with prognosis $(35,36)$. D310 was identified as the most common mtMSI of mtDNA, and the D310 somatic mutation has been reported as a valuable biomarker for lung cancer diagnosis (37), associated with decreased risk for malignant fibrous histiocytoma (23) and increased T-ALL risk (17). In addition, it may be used as clonal marker for solid tumors (38). The T16189C variation has been reported in breast (39) and endometrial (40) cancer, and the $(\mathrm{CA})_{\mathrm{n}}$ repeat was associated with breast cancer survival rate (41). However, they have not been reported in patients with AML, and in the present study, no association was identified between the aforementioned variations and AML risk, which may be due to the different underlying pathogenesis of different cancer types.

In conclusion, the D-loop region of mtDNA is of high variability, the current case-control study revealed that $\mathrm{T} 152 \mathrm{C}$ was associated with AML risk, particularly the AML-M3 subtype; however, no associated was identified with clinical characteristics or chemotherapy response. The T152C variation may participate in AML pathogenesis via enhancing the replication of $\mathrm{O}_{\mathrm{H}}$, leading to over proliferation. This variation maybe a diagnostic biomarker; however, further studies with larger sample sizes are warranted for verification of the results of the present study.

\section{Acknowledgements}

The presentstudy was supported by the National Natural Science Foundation of China (grant nos. NSFC-81401727 and NSFC-81071425).

\section{References}

1. Dohner H: Implication of the molecular characterization of acute myeloid leukemia. Hematology Am Soc Hematol Educ Program: 412-419, 2007.

2. Abdel-Wahab O and Levine RL: Mutations in epigenetic modifiers in the pathogenesis and therapy of acute myeloid leukemia. Blood 121: 3563-3572, 2013.

3. Ghanem H, Tank N and Tabbara IA: Prognostic implications of genetic aberrations in acute myelogenous leukemia with normal cytogenetics. Am J Hematol 87: 69-77, 2012.

4. Im AP, Sehgal AR, Carroll MP, Smith BD, Tefferi A, Johnson DE and Boyiadzis M: DNMT3A and IDH mutations in acute myeloid leukemia and other myeloid malignancies: Associations with prognosis and potential treatment strategies. Leukemia 28: 1774-1783, 2014

5. Komanduri KV and Levine RL: Diagnosis and Therapy of Acute Myeloid Leukemia in the Era of molecular risk stratification. Annu Rev Med 67: 59-72, 2016.

6. Warburg O: On respiratory impairment in cancer cells Science 124: 269-270, 1956. 
7. Anderson S, Bankier AT, Barrell BG, de Bruijn MH, Coulson AR, Drouin J, Eperon IC, Nierlich DP, Roe BA, Sanger F, et al: Sequence and organization of the human mitochondrial genome. Nature 290: 457-465, 1981.

8. Shoffner JM and Wallace DC: Mitochondrial genetics: Principles and practice. Am J Hum Genet 51: 1179-1186, 1992.

9. Bianchi NO, Bianchi MS and Richard SM: Mitochondrial genome instability in human cancers. Mutat Res 488: 9-23, 2001.

10. Bendall KE, Macaulay VA, Baker JR and Sykes BC: Heteroplasmic point mutations in the human mtDNA control region. Am J Hum Genet 59: 1276-1287, 1996.

11. Lee SR and Han J: Mitochondrial Nucleoid: Shield and Switch of the Mitochondrial Genome. Oxid Med Cell Longev 2017: 8060949, 2017.

12. Ishikawa $\mathrm{K}$, Takenaga $\mathrm{K}$, Akimoto $\mathrm{M}$, Koshikawa $\mathrm{N}$, Yamaguchi A, Imanishi H, Nakada K, Honma Y and Hayashi J: ROS-generating mitochondrial DNA mutations can regulate tumor cell metastasis. Science 320: 661-664, 2008.

13. Lu J, Sharma LK and Bai Y: Implications of mitochondrial DNA mutations and mitochondrial dysfunction in tumorigenesis. Cell Res 19: 802-815, 2009.

14. Sultana GN, Rahman A, Shahinuzzaman AD, Begum RA and Hossain CF: Mitochondrial DNA mutations--candidate biomarkers for breast cancer diagnosis in Bangladesh. Chin J Cancer 31: 449-454, 2012.

15. Kabekkodu SP, Bhat S, Mascarenhas R, Mallya S, Bhat M, Pandey D, Kushtagi P, Thangaraj K, Gopinath PM and Satyamoorthy K: Mitochondrial DNA variation analysis in cervical cancer. Mitochondrion 16: 73-82, 2014.

16. Carew JS, Zhou Y, Albitar M, Carew JD, Keating MJ and Huang P: Mitochondrial DNA mutations in primary leukemia cells after chemotherapy: Clinical significance and therapeutic implications. Leukemia 17: 1437-1447, 2003.

17. Kwok CS, Quah TC, Ariffin H, Tay SK and Yeoh AE: Mitochondrial D-loop polymorphisms and mitochondrial DNA content in childhood acute lymphoblastic leukemia. J Pediatr Hematol Oncol 33: e239-e244, 2011

18. Yacoub HA, Mahmoud WM, El-Baz HA, Eid OM, ELfayoumi RI, Elhamidy SM and Mahmoud MM: Novel mutations in the displacement loop of mitochondrial DNA are associated with acute lymphoblastic leukemia: A genetic sequencing study. Asian Pac J Cancer Prev 15: 9283-9289, 2014.

19. Grist SA, Lu XJ and Morley AA: Mitochondrial mutations in acute leukaemia. Leukemia 18: 1313-1316, 2004

20. Sharawat SK, Bakhshi R, Vishnubhatla S and Bakhshi S Mitochondrial D-loop variations in paediatric acute myeloid leukaemia: A potential prognostic marker. Br J Haematol 149: 391-398, 2010.

21. Silkjaer T, Nørgaard JM, Aggerholm A, Ebbesen LH, Kjeldsen E, Hokland P and Nyvold CG: Characterization and prognostic significance of mitochondrial DNA variations in acute myeloid leukemia. Eur J Haematol 90: 385-396, 2013.

22. Sabattini E, Bacci F, Sagramoso C and Pileri SA: WHO classification of tumours of haematopoietic and lymphoid tissues in 2008: An overview. Pathologica 102: 83-87, 2010.

23. Xun J, Li Z, Song X and Wang X: Identification of sequence polymorphisms in the D-loop region of mitochondrial DNA as risk biomarkers for malignant fibrous histiocytoma. Mitochondrial DNA 26: 380-383, 2015.

24. Nishimaki Y, Sato K, Fang L, Ma M, Hasekura H and Boettcher B: Sequence polymorphism in the mtDNA HV1 region in Japanese and Chinese. Leg Med (Tokyo) 1: 238-249, 1999.

25. Mueller EE, Eder W, Ebner S, Schwaiger E, Santic D, Kreindl T, Stanger O, Paulweber B, Iglseder B, Oberkofler H, et al: The mitochondrial T16189C polymorphism is associated with coronary artery disease in Middle European populations. PLoS One 6: e16455, 2011.
26. Bandelt HJ, Kloss-Brandstätter A, Richards MB, Yao YG and Logan I: The case for the continuing use of the revised Cambridge Reference Sequence (rCRS) and the standardization of notation in human mitochondrial DNA studies. J Hum Genet 59: 66-77, 2014.

27. Lee H, Geng C, Cheng M, Lee Z and Guo Z: Single nucleotide polymorphisms in the mitochondrial displacement loop and age-at-onset of familial breast cancer. Mitochondrial DNA A DNA Mapp Seq Anal 27: 3082-3085, 2016

28. Li S, Wan P, Peng T, Xiao K, Su M, Shang L, Xu B, Su Z, Ye X and Peng N: Associations between sequence variations in the mitochondrial DNA D-loop region and outcome of hepatocellular carcinoma. Oncol Lett 11: 3723-3728, 2016.

29. Wang CY, Li H, Hao XD, Liu J, Wang JX, Wang WZ, Kong QP and Zhang YP: Uncovering the profile of somatic mtDNA mutations in Chinese colorectal cancer patients. PLoS One 6: e21613, 2011.

30. Hu WX, Ding CM, Li RJ, Fan HY, Guo ZJ and Liu W: Single nucleotide polymorphisms in the mitochondrial displacement loop and age-at-onset of non-small cell lung cancer. Genet Mol Res 14: 2512-2517, 2015.

31. Feng D, Xu H, Li X, Wei Y, Jiang H, Xu H, Luo A and Zhou F: An association analysis between mitochondrial DNA content, G10398A polymorphism, HPV infection, and the prognosis of cervical cancer in the Chinese Han population. Tumour Biol 37: 5599-6007, 2016

32. Lam ET, Bracci PM, Holly EA, Chu C, Poon A, Wan E, White K, Kwok PY, Pawlikowska L and Tranah GJ: Mitochondrial DNA sequence variation and risk of pancreatic cancer. Cancer Res 72: 686-695, 2012

33. Zhang J, Asin-Cayuela J, Fish J, Michikawa Y, Bonafe M, Olivieri F, Passarino G, De Benedictis G, Franceschi C and Attardi G: Strikingly higher frequency in centenarians and twins of mtDNA mutation causing remodeling of replication origin in leukocytes. Proc Natl Acad Sci USA 100: 1116-1121, 2003.

34. Wang Y, Michikawa Y, Mallidis C, Bai Y, Woodhouse L, Yarasheski KE, Miller CA, Askanas V, Engel WK, Bhasin S and Attardi G: Muscle-specific mutations accumulate with aging in critical human mtDNA control sites for replication. Proc Natl Acad Sci USA 98: 4022-4027, 2001

35. Lee JH, Hwang I, Kang YN, Choi IJ and Kim DK: Genetic characteristics of mitochondrial DNA was associated with colorectal carcinogenesis and its prognosis. PLoS One 10: $\mathrm{e} 0118612,2015$.

36. Lee DH, Lee JH, Kim DK and Keum DY: Nuclear and mitochondrial DNAs microsatellite instability and mitochondrial DNA copy number in adenocarcinoma and squamous cell carcinoma of lung: A pilot study. APMIS 123: 1048-1054, 2015.

37. Chen XZ, Fang Y, Shi YH, Cui JH, Li LY, Xu YC and Ling B: Mitochondrial D310 instability in Chinese lung cancer patients. Mitochondrial DNA A DNA Mapp Seq Anal 27: 1177-1180, 2016.

38. Geurts-Giele WR, Gathier GH, Atmodimedjo PN, Dubbink HJ and Dinjens WN: Mitochondrial D310 mutation as clonal marker for solid tumors. Virchows Arch 467: 595-602, 2015.

39. Tipirisetti NR, Govatati S, Pullari P, Malempati S, Thupurani MK, Perugu S, Guruvaiah P, Rao KL, Digumarti RR, Nallanchakravarthula V, et al: Mitochondrial control region alterations and breast cancer risk: A study in South Indian population. PLoS One 9: e85363, 2014.

40. Wang Y, Liu VW, Tsang PC, Chiu PM, Cheung AN, Khoo US, Nagley P and Ngan HY: Microsatellite instability in mitochondrial genome of common female cancers. Int J Gynecol Cancer 16 (Suppl 1): S259-S266, 2006.

41. Ye C, Gao YT, Wen W, Breyer JP, Shu XO, Smith JR, Zheng W and Cai Q: Association of mitochondrial DNA displacement loop (CA)n dinucleotide repeat polymorphism with breast cancer risk and survival among Chinese women. Cancer Epidemiol Biomarkers Prev 17: 2117-2122, 2008. 